\title{
Development of a Predictive Model for Removal of Organic Matter from Leachate Landfill by Catalytic Oxidation Using Response Surface Methodology
}

\author{
Milton Rosero-Moreano ${ }^{1, *}$, Cristina Nerín² \\ ${ }^{1}$ Grupo de Investigación en Cromato grafía y Técnicas Afines GICTA, Departamento de Química, Universidad de Caldas. Calle 65 Nº 26-10 \\ Sede Principal A.A: 275, Manizales-Caldas-Colombia \\ ${ }^{2}$ Universidad de Zaragoza, I3A, Escuela de In geniería y Arquitectura EINA Campus Ebro Departamento de Química Analítica C/ Maria de \\ Luna 350018 Zaragoza-Spain
}

\begin{abstract}
In this work the heterogeneous Fenton catalytic experiments were arranged in a CCF experimental design and analyzed by response surface methodology, for every peroxide concentration. These response surfaces were the representation of a quadratic predictive model developed for improving of biochemical oxygen demand at five days/chemical oxygen demand $\left(\mathrm{BDO}_{5} / \mathrm{COD}\right)$ ratio, trough the optimization parameters of reaction. For this proposal 18 catalytic tests were carried out evaluating three main factors: peroxide concentration, catalyst loading and the peroxide addition rate. The results in confronting with the experimental data showed that from 60 minutes the catalytic wet peroxide oxidation (CWPO) reaction was stationated in focusing the chemical COD removal, inclusively in any opportunities these values were decreased maybe because new compounds had been formed and we supposed that these new compounds were with biodegradable character because this behavior was perfectly answered by the prediction model, hence with this new and enhancent ratio there are possibilities to get in to the biological process again for the refine the effluent and comply with the actual regulation. The best conditions predicted for the model are at $4.68 \mathrm{M}$ peroxide concentration, catalyst loading charge $(\mathrm{CL})(0.5-0.6 \%)$ and pero xide addition rate (PAR) $(7.5-10 \mathrm{~mL} / \mathrm{h})$ to improve its biodegradability to 0.30 , thus this effluent might come back to the begin of plant for refining the treatment.
\end{abstract}

Keywords Leachate of Landfill, CWPO, RSM

\section{Introduction}

Landfill is nowadays the main way of disposal for the enormous charge of municipal solid wastes generated all around the world[1]. However, rain and liquid percolation throughout them provokes the side production of significant volumes of a strongly contaminant liquid, the so-called leachate of landfill. In general terms, it is a dark liquid of offensive odor, high loading of organic compounds and complex chemical composition, which usually includes not negligible charge of bio-reluctant compounds[2]. Catalytic wet peroxide oxidation CWPO is a green technology that meets the characteristics required to perform efficiently in the treatment of such highly contaminant streams. In CWPO the hydrogen peroxide is the source of the powerfulhydro xyl radicals, whose generation can be activated by using ine xpensive solid catalysts like $\mathrm{A} / \mathrm{Fe}$-pillared clays, and the

* Corresponding author:

milton.rosero@ucaldas.edu.co (Milton Rosero-Moreano)

Published online at http://journal.sapub.org/aac

Copyright (C 2012 Scientific \& Academic Publishing. All Rights Reserved process can be efficiently carried out at very mild conditions of ambient temperature and pressure. The employ ment of a solid catalyst enables both, efficient immobilization of the active metal that avoids its recovery from the effluent as one extra step, as well as the catalyst reuse along several reaction catalytic cycles[3]. One of the tools that have broughtsignificant benefits when optimizing analytical processes in which several variables simultaneously affect the analysis, is the experimental design based on factorial design[4] and response surface methodology [5]

The aim of this work was to develop a response surface methodology (RSM) to find a model able to predict the optimum parameters of reaction improving either, COD removal, $\mathrm{BOD}_{5} / \mathrm{COD}$ ratio of the output stream or both, employing for that purpose a central composite face (CCF) quadratic experimental design tool.

\section{Experimental}

\subsection{Leachate Characteristics}

The leachate employed in the catalytic runs was perfectly described in Galeano et al[3] and all data used for this 
development are from the joint work at the University of Nariño [6]

\subsection{Experimental Design}

The catalytic tests were carried out in two batches: one batch at $2.34 \mathrm{~mol} / \mathrm{L}$ of the peroxide concentration (PC) and another one at $4.68 \mathrm{~mol} / \mathrm{L} \mathrm{H}_{2} \mathrm{O}_{2}$. In Table 1 it is shown the arrangement of the 18 catalytic tests carried out by duplicate using a central composite face (CCF) quadratic experimental design. The other two factors were tested at three levels each one: catalyst loading (CL) of $0.5,1.0$ and $2.0\left(\mathrm{~g}_{\mathrm{NaBVAlF}} 3 / 100\right.$ $\left.\mathrm{mL}_{\text {leachate }}\right)$ and the peroxide addition rate (PAR) of $7.5,15$ and $30(\mathrm{~mL} / \mathrm{h})$.

\section{Results and Discussion}

\subsection{Design of Experiments}

Since all the trends till now found for every factor at a time have shown to strongly depend on the chosen conditions for the rest of parameters, their simu ltaneous observation was tried to get better insight of the experimental system. The central composite face design CCF constituted by a full or fractional factorial design and center points placed in the faces, is one class of response surface methodologies often used for fitting of second-order models in the design of experiments [7]. The CCF was used in this work, considering the minimum and maximum levels for $\mathrm{H}_{2} \mathrm{O}_{2}$ concentration $(2.34-4.68 \mathrm{~mol} / \mathrm{L})$, catalyst loading $(0.5$ $-2.0 \mathrm{wt} . / \mathrm{V} \%)$, and rate of peroxide addition $(7.5-30 \mathrm{~mL} / \mathrm{h})$ and two responses: $\mathrm{COD}$ removal and $\mathrm{BI}\left(\mathrm{BOD}_{5} / \mathrm{COD}\right.$ ratio). Assuming a second-order polynomial model, at least 18 replicated runs (36 experiments) must be carried out to solve the matrix, for which statistical software MODDE v6.0 was used. Each run was replicated to check the reproducibility and to evaluate the experimental error of the results obtained in the design of experiments (DOE). The 36 experiments are put together in the 18 replicated runs listed in Table 1. A random order was employed to perform the experiments in order to minimize systematic errors. As above mentioned, the targeted responses to be maximized were both, the COD removal and the BI value.

Table 1. Full CCF quadratic experimental design of the catalytic tests

\begin{tabular}{|c|c|c|c|c|c|c|}
\hline Run & $\begin{array}{l}{\left[\mathrm{H}_{2} \mathrm{O}_{2}\right]} \\
(\mathrm{mol} / \mathrm{L}) \\
\end{array}$ & $\begin{array}{c}\mathrm{CL} \\
\text { (wt./V \%) }\end{array}$ & PAR (mL/h) & $\begin{array}{r}\mathrm{H}_{2} \mathrm{O}_{2} / \mathrm{Fe}_{(\mathrm{s})}{ }^{a} \\
(\mathrm{~mol} / \mathrm{mol})\end{array}$ & $\begin{array}{l}\text { COD Removal } \\
\left( \pm \mathrm{u}_{\mathrm{remCOD}}\right)^{c}(\%) \\
\end{array}$ & $\begin{array}{l}\mathrm{BOD}_{5} / \mathrm{COD}^{b} \\
\left( \pm \mathrm{U}_{\mathrm{BOD} / \mathrm{COD}}\right)^{c}\end{array}$ \\
\hline 1 & & 0.5 & 7.5 & 109 & $16( \pm 3)$ & $0.119( \pm 0.004)$ \\
\hline 2 & & 0.5 & 15 & 213 & $23( \pm 3)$ & $0.135( \pm 0.004)$ \\
\hline 3 & & 0.5 & 30 & 414 & $33( \pm 3)$ & $0.167( \pm 0.004)$ \\
\hline 4 & & 1.0 & 7.5 & 54 & $28( \pm 2)$ & $0.081( \pm 0.001)$ \\
\hline 5 & 2.34 & 1.0 & 15 & 107 & $36( \pm 5)$ & $0.229( \pm 0.008)$ \\
\hline 6 & & 1.0 & 30 & 207 & $12( \pm 5)$ & $0.166( \pm 0.011)$ \\
\hline 7 & & 2.0 & 7.5 & 27 & $27( \pm 5)$ & $0.203( \pm 0.011)$ \\
\hline 8 & & 2.0 & 15 & 53 & $9 \quad( \pm 3)$ & $0.094( \pm 0.004)$ \\
\hline 9 & & 2.0 & 30 & 103 & $11( \pm 5)$ & $0.190( \pm 0.010)$ \\
\hline 10 & & 0.5 & 7.5 & 217 & $25( \pm 3)$ & $0.292( \pm 0.004)$ \\
\hline 11 & & 0.5 & 15 & 427 & $21( \pm 3)$ & $0.321( \pm 0.004)$ \\
\hline 12 & & 0.5 & 30 & 827 & $17( \pm 3)$ & $0.269( \pm 0.004)$ \\
\hline 13 & & 1.0 & 7.5 & 108 & $41( \pm 6)$ & $0.275( \pm 0.013)$ \\
\hline 14 & 4.68 & 1.0 & 15 & 213 & $48( \pm 3)$ & $0.166( \pm 0.004)$ \\
\hline 15 & & 1.0 & 30 & 413 & $39( \pm 5)$ & $0.246( \pm 0.010)$ \\
\hline 16 & & 2.0 & 7.5 & 54 & $50( \pm 6)$ & $0.282( \pm 0.010)$ \\
\hline 17 & & 2.0 & 15 & 106 & $9 \quad( \pm 4)$ & $0.171( \pm 0.006)$ \\
\hline 18 & & 2.0 & 30 & 206 & $39( \pm 5)$ & $0.302( \pm 0.013)$ \\
\hline
\end{tabular}

${ }^{a}$ Time of reaction $1.0 \mathrm{~h}$.

${ }^{b}$ Time of reaction $4.0 \mathrm{~h}$.

${ }^{c}$ Uncertainty was calcul ated as random error through propagation error in linear reg ression and arithmetic calculations 
The probability values ( $p$ value) from the analysis of variance for models COD removal and BI were 0.053 and 0.002 respectively. It allowed us to conclude that quadratic model developed is statistically poor to predict COD removal but good for BI enhancement (with a 95\% confidence level) and therefore is appropriate for predicting the BI response in $4 \mathrm{~h}$ of reaction $(\mathrm{p}<0.05)$. Moreover, the determination coefficient $\left(\mathrm{R}^{2}\right)$, which is also included in the inspection of the fitting between the experimental data and the mathematical model is 0.60 , indicating that the model can explain at least $60 \%$ of the targeted function variations. Finally, in the analysis of variance the F value (4.26) is higher than the value from Fisher tables $\left(F_{9,26}=2.22\right.$, for a 95\% confidence level), meaning that the variations in the response are related to the model and not to random variations. Then, BI was the only response found more or less acceptable to continue with a model formulation, in order to estimate the more promising levels of the factors required to improve the performance of the CWPO reaction applied on the leachate of landfill. The unacceptable fitting observed for COD re moval response probably arose to above discussed order kinetics change in peroxide reaction, taking place in the range of $\mathrm{H}_{2} \mathrm{O}_{2} / \mathrm{Fe}_{(\mathrm{s})}$ mole ratios here studied, which could not have been correctly accounted by the model. The very important role of the $\mathrm{H}_{2} \mathrm{O}_{2} / \mathrm{Fe}$ (II) mole ratio on the performance of Fenton homogeneous systems for treatment of leachates of landfill has been pointed out by Zhang et al. [8] short time ago, but also underlined more recently by employing a multivariate approach [9]. Besides, the implicit blind effect of contaminant adsorption on the clay catalyst probably contributed too. Likewise, the more acceptable fitting for BI was observed, probably because regardless the kinetics followed by the peroxide reaction it anyway led to improve biodegradability either, via $\mathrm{BOD}_{5}$ enhancing in the not-activated pathway or COD removal by the radical mediated one. Thus, using the above-mentioned software the coefficients of the BI predicting quadratic model in the polynomial expression were calculated by multiple nonlinear regression analysis, resulting in the following regression equation:

$\mathrm{BI}=-121,935+0.027 * \mathrm{PC}-0.003^{*} \mathrm{CL}+0.007 * \mathrm{PAR}+$ $125,419 * \mathrm{PC}^{2}+0.012 * \mathrm{CL}^{2}+0.010 * \mathrm{PAR}^{2}-0.010 * \mathrm{PC} * \mathrm{CL}-$ $0.004 * \mathrm{PC} * \mathrm{PAR}+0.003 \mathrm{CL} * \mathrm{PAR}$

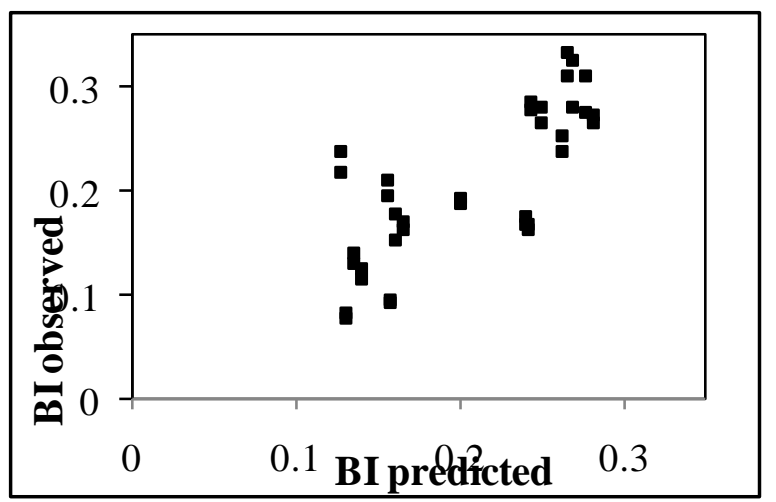

Figure 1. Experimental and calculated result sprovided by the RSM model for output biodegradability index of leachate at $4 \mathrm{~h}$ of reaction
Figure 1 shows the predicted BI values from this equation as compared to the experimental data at $4 \mathrm{~h}$ of reaction. From this plot, it can be seen that the values predicted by the second-order model agree reasonably with the experimental data, even though the simplified equation has been used. Obviously, the data would fit better as the complete equation obtained from MODDE software is used. Thus, the behavior of the response factor BI was predicted by a model as follows in next paragraph.

\subsection{Modeled Response for Biodegradability Index B I}

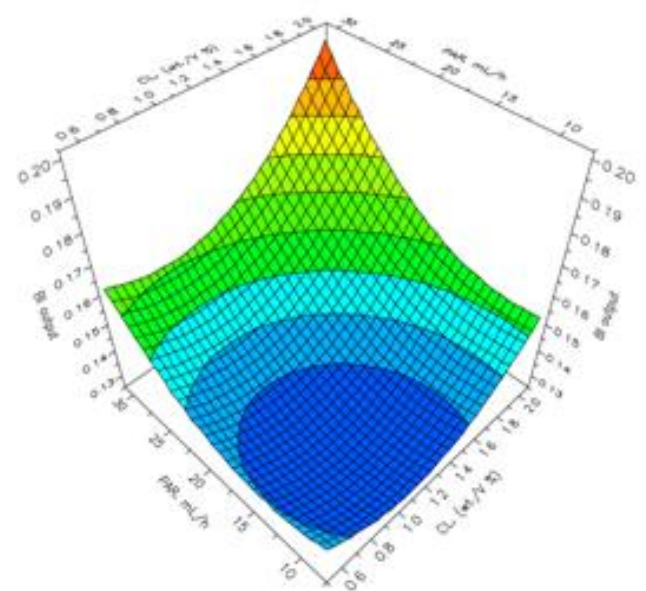

(a)

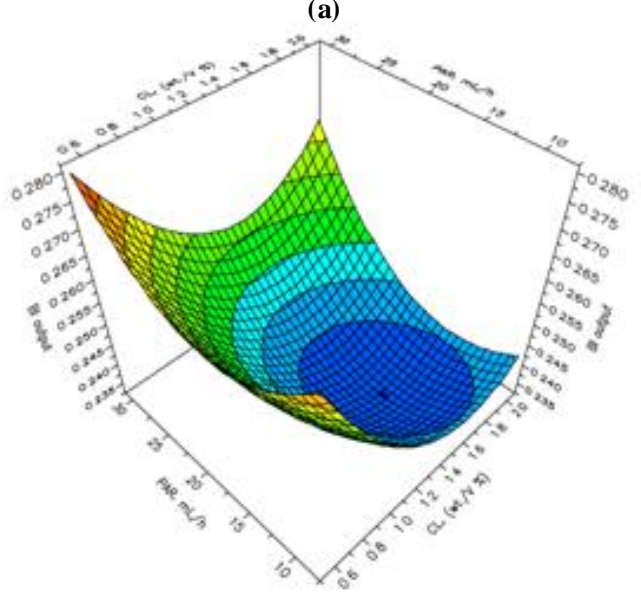

(b)

Figure 2. Response surface plots for biodegradability index predicted at different peroxide concentrations. (a) $[\mathrm{H} 2 \mathrm{O} 2]=2.34 \mathrm{~mol} / \mathrm{L} ;(\mathrm{b})[\mathrm{H} 2 \mathrm{O} 2]=$ $4.68 \mathrm{~mol} / \mathrm{L}$

As it can be seen in the response surfaces generated by the model equation (Figure 2), there is an important influence exerted by the pero xide concentration and dosage on relevant increase in the BI ratio under different conditions. First of all, while maximu $\mathrm{m}$ BI enhancement obtained for low peroxide concentration is slightly over 0.20 , in the case of the higher peroxide concentration is close to 0.30 , showing as expected that an increased dosage of oxidizing agent may lead to higher enhancement in the output biodegradability. Moreover, more remarkable seems that under low peroxide concentration $(2.34 \mathrm{~mol} / \mathrm{L}) \mathrm{BI}$ was enhanced at high $\mathrm{CL}$ $(2.0 \%)$ and PAR values $(30 \mathrm{~mL} / \mathrm{h})$, while under high peroxide concentration $(4.68 \mathrm{~mol} / \mathrm{L})$ such conditions were 
exactly the opposite respect to the catalyst, with the BI rising at lower CL of $0.5 \%$ and high PAR of $30 \mathrm{~mL} / \mathrm{h}$. It is also here noteworthy that under high peroxide concentration the BI is enhanced at low catalyst loading, almost irrespective from the PAR values (Figure 2 (b)). It coincides with the explanation offered in advance for single effects, on the basis of differing oxidation potentials of the species responsible to carry out the organic depletion either, when catalytic activation would prevail leading to radical formation (high $\mathrm{CL}$ and/or low PAR) or when direct oxidation by molecular $\mathrm{H}_{2} \mathrm{O}_{2}$ could be promoted (low $\mathrm{CL}$ and/or high PAR). In other words, the model anticipates that when high PC and low CL values are employed the $\mathrm{BI}$ enhancement occurs almost exclusively due to direct action of the peroxide on the organ ic matter with no mediated catalytic activation. Meanwhile, under low peroxide concentration BI enhancement results promoted by a high catalyst loading, for sure because catalytic activated radicals play a more important role on biodegradability under such conditions by means of both, COD removal as well as higher $\mathrm{BOD}_{5}$ enhancing.

\subsection{Overall Performance}

The overall performance of the heterogeneous CWPO reaction must be carefully analyzed taking into account not only the modeled predicted BI response but also the experimental results obtained for the COD removal[3]. It is evident that high catalyst loadings together with low peroxide addition rates and peroxide dosages seem to promote a better use of the oxidizing agent towards COD removal, whose direct consequence drives to lower costs of operation. Furthermore, as said in last paragraph the better predicted reaction parameters for $\mathrm{BI}$ enhancement are at first apparently the opposite of those needed to achieve the highest COD removal. However, in Figure 2 (b) can be seen that $\mathrm{BI}$ response surface at high $\mathrm{PC}$ exhibits another maximum, though a bit less pronounced, for high CL and high PAR which can also be seen at low PC (see Figure 2 (a)). Run 18 in Table 1 meets such a pair of reaction parameters at high peroxide concentration and dosage, while shows a reasonable high COD removal close to $40 \%$. It indicates that modeled BI offers several possible sets of conditions to maximize its response, including some where moderate to high COD removals can also be achieved at the same time. It can be briefly summarized as follows. Although the commented lower intrinsic oxidizing power displayed by not-activated molecular hydrogen peroxide compared to hydroxyl radicals leads to increased biodegradability in the output leachate, it is not necessarily accompanied by a significant COD removal. Apparently, when the reaction is driven preferentially following such a pathway, there is an important $\mathrm{BOD}_{5}$ increment but scarce COD depletion, which anyway conduces to higher biodegradability in the output stream (see runs 11 and 12 at Table 1). In the other hand, as high catalyst loadings are employed, in fact if we speak about lower $\mathrm{H}_{2} \mathrm{O}_{2} / \mathrm{Fe}_{(\mathrm{s})}$ mole ratios (Table 1) it could result more accurate, the role played by the catalytically-generated radical species becomes fairly more important. Under this scenario COD removal results clearly favored on BI enhancement (see runs 4 and 16 at Tab le 1) probably because the powerful radicals conduce to deeper oxidation and higher degree of mineralization, though generating lower fraction of by-products featuring enhanced biodegradability. Neverthel ess, it must be stressed that such behavior strongly depends also on peroxide concentration and dosage.

\section{Conclusions}

CCF experimental design was used to arrange the catalytic experiments, and a response surface methodology was applied to data, where an acceptable predicting model was obtained only for BI response while poor fitting prevented to find out another one for COD removal response.

\section{ACKNOWLEDGEMENTS}

M. Rosero-Moreano gratefully thanks to chemists Melba Tutalcha and Jazmin Figueroa for their precious work. The authors thanks also to Gobierno de Aragón (Spain), Grupo GUIA, Grupo consolidado de Investigación T-10.

\section{REFERENCES}

[1] S. Renou, J.G. Givaudan, S. Poulain, F. Dirassouyan, P. Moulin, "Landfill leachate treatment: Review and opportunity", Elsevier, Journal of Hazardous Materials, vol. 150, pp. $468-493,2008$.

[2] G Tchobanoglous, F. Kreith. Handbook of solid waste management. Mc Graw-Hill, 2nd ed., New York, 2002.

[3] Luis Alejandro Galeano, Miguel Angel Vicente, Andony Gil, "Treatment of municipal leachate of landfill by Fenton-like heterogeneous catalytic wet peroxide oxidation using an A1/Fe-pillared montmorillonite as active catalyst", Elsevier, Chemical Engineering Journal, vol. 178, pp. $146-$ $153,2011$.

[4] Mauricio Aguirre-Gonzalez, Gonzalo Taborda-Ocampo, CarmenDussan-Lubert, Cristina Nerín, Milton Rosero-Moreano, "Optimization of the HS-SPME technique by using response surface methodology for evaluating chlorine disinfection by-products by GC in drinking water", Sociedade Brasileira de Quimica, Journal of Brazilian Chemical Society, vol. 22, no. 12, pp. 2330 - 2336, 2011.

[5] Milton Rosero-Moreano, Mauricio Aguirre, Davinson Pezo, Gonzalo Taborda, Carmen Dussán, Cristina Nerín, "Solventless microextraction techniques for determination of trihalomethanes by gas chromatography in drinking water", Springer, Water Air and Soil Pollution, vol. 223, pp. $667-$ 678, 2012.

[6] Jazmin Figueroa, Melva Tutalcha, "Evaluación de una arcilla modificada con hierro en la oxidación catalítica de carga orgánica presente en lixiviados producidos en el Relleno 
Sanitario Antanas (RSA) de Pasto", Tesis de Grado Químico. Universidad de Nariño, Colombia, 2008.

[7] D. Montgomery. Design and Analy sis of Experiments. John Wiley and Sons, New Jersey, 6th. Edition, 2005.

[8] H. Zhang, H.J. Choi, C-P. Huang, “Optimization of Fenton Process for the treatment of landfill leachate", Elsevier,
Journal of Hazardous Materials, vol. B125, pp. 166 - 174, 2005.

[9] H. Zhang, H.J. Choi, P. Canazo, C-P. Huang, "Multivariate approach to the Fenton process for the treatment of landfill leachate", Elsevier, Journal of Hazardous Materials, vol. 161, pp. $1306-1312,2009$. 